\title{
Splendor de lo cotidiano. Objetos dorados de una aldea medieval madrileña (Ermita Virgen de la Torre, Vicálvaro-Vallecas)
}

\author{
Alexandra UsCATESCU \\ Universidad Complutense de Madrid \\ Departamento de Historia del Arte I (Medieval) \\ alexandra.uscatescu@ghis.ucm.es
}

RESUMen

Se analiza una serie de hallazgos metálicos de adorno procedentes de las excavaciones arqueológicas en el yacimiento medieval de la Ermita Virgen de la Torre (Madrid), así como de cuatro piezas inéditas del Museo Arqueológico Nacional. El artículo aborda específicamente la contextualización históricocultural de las placas de cinturón doradas de carácter para-heráldico que se relacionarían con parámetros culturales cristianos (connotación positiva de los animales y objetos representados, paños "scutulados"), y que se contrapondrían a los hábitos decorativos del mundo andalusí entre los siglos XII-XIII.

Palabras clave: Almohades, Castillos, Dorado al fuego, Ermita Virgen de la Torre, Hebillas para-heráldicas, Leones, Lobos, Museo Arqueológico Nacional, Reinos cristianos.

\section{Daily Splendor. Gilded Objects from a Medieval Village near Madrid (Ermita Virgen de la Torre, Vicálvaro-Vallecas)}

\begin{abstract}
A series of metallic ornaments recovered from the archaeological excavations at the medieval site of Ermita Virgen de la Torre (Madrid) is here discussed, as well as several unpublished pieces preserved at the Museo Arqueológico Nacional. This paper specifically addresses the historical and cultural contextualization of a group of gilded belt-bluckes that exhibits a para-heraldic decoration, which could be related to Christian cultural parameters (a positive connotation of animals and objects represented, "scutulados" clothes) that could be opposed to the decorative practices of al-Andalus between $12^{\text {nd }}-13^{\text {rd }}$ centuries.
\end{abstract}

Key words: Almohads, Castles, Christian Kingdoms, Ermita Virgen de la Torre, Lions, Mercure Gilding, Museo Arqueológico Nacional, Para-heraldic Buckles, Wolves. 
El objeto de este trabajo es dar a conocer una serie de piezas de adorno exhumadas en las excavaciones realizadas en la Ermita Virgen de la Torre, en Madrid ${ }^{1}$ : en un paraje situado al pie del cerro Almodóvar y a la orilla del antiguo arroyo de Los Migueles, cuyo hábitat inicial se remonta a época romana alto-imperial ${ }^{2}$. Tras un hiato de poco más de dos siglos, la zona vuelve a ser ocupada en el s. V con la instalación de una serie de cabañas estacionales que se pueden vincular a la trashumancia tradicional de la zona, pues la Cañada Real se encuentra a tan sólo $2 \mathrm{~km}$ al SE del yacimiento. Mediado el s. VII, el hábitat se torna más estable conformándose una pequeña aldea testimoniada por la construcción de hornos y edificios de planta cuadrangular con basamentos de mampostería de sílex y elevación de muros de tapial, cubiertos por tejas. A esas casas se asocian estructuras de almacenaje o silos subaéreos, pozos, piletas y hornos metalúrgicos. Es difícil establecer qué estructuras sobrevivieron a la conquista islámica y cuáles no, e incluso si ésta afectó mínimamente a la aldea tardo-antigua. Se han podido datar algunas actividades edilicias entre los ss. X-XI, por lo que se asume una continuidad del hábitat entre la segunda mitad del s. VII y el s. IX. Algunas de las estructuras tardo-antiguas fueron abandonadas y colmatadas con restos de cerámica de época islámica (ss. IX-X): es el caso de una cueva artificial con dos cámaras circulares abovedadas. Otras estructuras excavadas fueron reutilizadas como basureros, mientras que ciertas actividades constructivas están bien fechadas en época califal, como la calzada construida a base de un nivel drenante de nódulos de sílex, con un nivel de circulación de barro en la parte superior. También la actividad minera extractiva relacionada con la explotación de sílex y yeso de forma extensiva se remonta a la ocupación islámica de la aldea ${ }^{3}$, y se extiende hasta el s. XX.

La mayoría de los medievalistas ha asumido que la primera alusión a esta aldea se registra en un documento de venta de 1205 que menciona una propiedad de Pedro Moro y su hijo Fernando probablemente conversos, en «Turre del Campo» ${ }^{4}$. Por lo que muchos supusieron que el nombre de la aldea correspondía a un topónimo de Reconquista y que los habitantes cristianos se habrían aglutinado alrededor de una antigua torre islámica cuya existencia no ha podido ser confirmada por las excavaciones ${ }^{5}$ : el único resto probable de estructura turriforme correspondería a un basamento cuadrangular de gruesas paredes de mampostería, datado en época romana, y ubicado

1 Excavación arqueológica dirigida por la autora, ejecutada por la empresa ARQUEOMEDIA y financiada por la Junta de Compensación de Los Berrocales, entre los años 2006 y 2010. Esta investigación se enmarca dentro del proyecto HAR2013-45578-R.

2 A. USCATESCU y A. FUENTES, "La Ermita Virgen de la Torre (Vallecas-Vicálvaro): un espacio altoimperial ¿artesanal o comercial?", Actas de las VI Jornadas de Patrimonio Arqueológico en la Comunidad de Madrid, Madrid, 2012, pp. 83-97.

3 A. USCATESCU, "La Ermita Virgen de la Torre (Vicálvaro): de aldea romana al despoblado medieval de Torrepedroso", La Ilustración de Madrid, 22 (2011-2012), pp. 201-208.

4 F. FITA, "Madrid desde el año 1203 hasta el de 1227", Boletín de la Real Academia de la Historia, 8 (1886), p. 320.

5 I. DUQUE y L. BARTOLOMÉ, "Despoblados de la Comunidad de Madrid. En busca de los términos perdidos", Alfoz, 40 (1987), pp. 51-52; M. FERNÁNDEZ MONTES, "El territorio de Vallecas en la Edad Media", M. FERNÁNDEZ MONTES (ed.), Vallecas: historia de un lugar de Madrid, Madrid, 2002, p. 59; F. JIMÉNEZ DE GREGORIO, "Notas geográfico-históricas de los pueblos de la actual provincia de Madrid en el siglo XVIII (continuación)", Anales del Instituto de Estudios Madrileños, 13 (1976), nota 39. 
dentro del cercado de la actual ermita. Lo que sí es significativo es que los hallazgos desde el s. XIII en adelante sean cada vez más escasos, destacando una moneda de plata del s. XV y fragmentos de loza toledana; pero, salvo las actividades mineras que se extienden hasta el s. XX, no hay evidencias de ninguna estructura de hábitat relacionada con el período tardo-medieval (s. XIV). De igual modo, las fuentes escritas permanecen en silencio hasta finales del s. XVI cuando la aldea aparece mencionada en los cuestionarios de Felipe II, concretamente en las respuestas de Vicálvaro de 1575 y 1578, donde la aldea se denomina «Torre el Pedroso», un topónimo que sin duda hace referencia a la abundancia de piedras de sílex ${ }^{6}$. En las Relaciones Topográficas, se describe como un despoblado, con una iglesia y unos pocos habitantes, junto a antiguos edificios abandonados. La iglesia habría sido parroquia hasta inicios del s. XVI, cuando un texto menciona el curato de $\left\langle L a\right.$ Torre» ${ }^{7}$, convirtiéndose en ermita cuando la aldea se despuebla. Nada sabemos del templo medieval, pero no es descartable que sus restos se encuentren bajo el edificio tardo-barroco. En 1780, otro texto eclesiástico vuelve a mencionar la ermita (descripción del cura don José Antonio Malueros) y en este caso podemos estar seguros que se trata del edificio actual ${ }^{8}$, pues sobre una ventana de la sacristía se encuentra una inscripción que indica la fecha de $1746^{9}$.

\section{Las piezas doradas de la Ermita Virgen de La Torre y su contexto arqueológico}

El conjunto de piezas metálicas que aquí se presenta está formado por placas de cinturón, hebillas o arreos de montura o apliques que han permanecido inéditos hasta su reciente restauración ${ }^{10}$. Aunque corresponden a objetos modestos de la vida cotidiana, su hallazgo resulta de interés científico por varios motivos, pero principalmente porque la cultura material que los acompaña nos permite ubicarlos en un marco cronológico situado entre los ss. X-XIII. Este dato es relevante por cuanto la mayoría conocida de estos adornos procede de colecciones privadas o de fondos de museos y suele carecer de ese tipo de vectores contextualizadores, por lo que las atribuciones cronológicas resultan deficitarias. Por no mencionar que este tipo de objetos, por su propio valor, tiende a alargar su vida útil más allá de su manufactura. Las piezas metálicas han sido recuperadas en distintos contextos arqueológicos; la más moderna, y la excepción, corresponde a un aplique con cabeza en forma de roseta, posiblemente

6 C. VIÑAS y R. PAZ, Relaciones histórico-geográficas-estadísticas de España hechas por iniciativa de Felipe II: Provincia de Madrid, Madrid, 1949, p. 529.

7 M.C. MARTÍN RUBIO, "Renacimiento y Siglo de Oro en el lugar de Vallecas", M. FERNÁNDEZ MONTES (ed.), Vallecas: historia de un lugar de Madrid, Madrid, 2002, p. 131, y p. 170.

8 F. JIMÉNEZ DE GREGORIO, op. cit., 1976, p. 148.

9 J.M. AZCÁRATE, Inventario artístico de la provincia de Madrid, Madrid, 1970, p. 304; aunque aparece mencionado como "Ermita de la Virgen de las Torres".

10 Las piezas $n^{\circ}$ 6-8 (Fig. 1) se han restaurado en el Laboratorio del SECYR de la Universidad Autónoma de Madrid, dentro del "Proyecto Láser: aplicación de las tecnologías láser en la conservación y restauración de los metales arqueológicos” (HAR2008-05175/HIST.MICINN) dirigido por el Dr. J. Barrio de la UAM. Mientras que los objetos $n^{\circ}$ 1-5 (Fig. 1) han sido restaurados por E. Cruz, restauradora autónoma. 
fechado hacia el s. XIV (Fig. 1,1). En la amortización de una antigua calicata minera para la extracción de sílex, se recuperó un pequeño cascabel del s. X con restos de dorado y una banda en relieve con una decoración sencilla de trazos oblicuos, incluso conserva la piedrecilla de cuarzo que suena al moverse (Fig. 1,2). Otros objetos de adorno se pueden fechar entre los ss. X-XI, como una placa de cinturón de latón dorado con una sencilla decoración de círculos impresos (Fig. 1,6), así como varias hebillas simples o dobles de cobre o bronce, en este caso, sin rastro de dorado (Fig. 1,3-5). Entre todos estos objetos, destaca un par de piezas de cinturón de cobre dorado (Fig. 1,7-8), manufacturadas con mercurio o "dorado al fuego" ", que quizá podrían vincularse a un taller recientemente reconocido en Calatrava la Vieja (Ciudad Real), donde un equipo de la Universidad Autónoma de Madrid dirigido por el profesor Barrio ha determinado la existencia de ciertos patrones técnicos que permitirían establecer una diferenciación entre las manufacturas andalusíes y las cristianas de Reconquista, siendo en estas últimas característico el empleo de una ratio oro-mercurio (Au: $\mathrm{Hg})$ más elevada que, sencillamente, se traduciría en un color dorado más intenso de las piezas de los reinos cristianos, como ha documentado Chamón ${ }^{12}$. En este sentido, no sólo el alto número de piezas doradas al fuego localizadas en Calatrava hace que se suponga, como hipótesis de trabajo, la existencia de un taller orfebre local, sino que también la cercanía de las minas de mercurio de Almadén resultaría cuanto menos significativa para la ubicación geográfica de ese hipotético taller medieval.

Entre todas las piezas, llama la atención una placa decorada con un león pasante a la izquierda (Fig. 1,8), cuya manufactura y tipología es coincidente con algunas piezas asociadas a ese hipotético taller castellano que incluye también algunas placas esmaltadas, simples o dobles, ensambladas mediante remaches. Todas estas piezas de cinturón suelen presentar un tipo de hebilla morfológicamente distintiva, simple o doble, acabada en una barra rectangular y con laterales de forma elíptica en el interior y ligeramente en ángulo en el exterior. La placa está formada por una lámina rectangular de cobre dorado doblada sobre sí misma, con un recorte extractivo rectangular en la zona correspondiente al orificio del hebijón para formar una doble charnela. En los extremos, presenta dos perforaciones para fijar la placa al cinturón, mediante remaches, no conservados. En la parte superior de esta placa es donde se centran los detalles de la silueta y anatomía del león (melena, garras y musculatura) y que, al igual que el campo del fondo de forma cuadrangular, están realizados con pequeñas impresiones de cincel de orfebre de impronta circular. Otra pieza madrileña completa permite ejemplificar esta clase de hebillas (Fig. 1,9).

La ornamentación de este tipo de placa de cinturón, criterios técnicos y estratigráficos aparte, aporta interesantes datos de tipo cultural que arrojarían luz sobre la estética y el valor otorgado a la indumentaria en poblaciones rurales, en tierras de

11 Los resultados de los análisis arqueométricos de las piezas de la Ermita Virgen de la Torre (Madrid) se han presentado recientemente en un congreso: P.C. GUTIÉRREZ-NEIRA, A.I. PARDO, M.C. MEDINA, A. CLIMENT-FONT, A. ZUCCHIATTI, A. USCATESCU, y J. BARRIO, "Análisis arqueométrico y restauración de un conjunto de hebillas del yacimiento "Ermita Virgen de la Torre", Actas del X Congreso Ibérico de Arqueometría (16-18 de octubre de 2013), Castellón, 2014, pp. 242-253.

12 J. CHAMÓN, Arqueometría, conservación y restauración de los metales dorados medievales, Tesis Doctoral, UCM, Madrid, 2010, p. 190; fig. 76. 
frontera. Por desgracia, el paralelo con la ilustración libraria coetánea se torna estéril. Es cierto que en diversos códices hispanos del s. XIII se advierten cintos, tahalíes, hebillas de cinturón o de sujeción de lorigas de caballos ${ }^{13}$. En concreto, Martín Ansón refiere algunos cinturones metálicos decorados con piedras o esmaltes figurados en algunas miniaturas del Códice Rico de las Cantigas de Alfonso $\mathrm{X}^{14}$, pero en el caso de las hebillas totalmente metálicas, nunca se aprecian detalles decorativos en estas ilustraciones que nos permitan comparar con la morfología y decoración de las placas de cinturón de los ss. XII-XIII ${ }^{15}$.

\section{El ornato personal en tierras de frontera: contrastes ideológicos}

Lamentablemente, la imagen del león pasante por sí misma poco puede aportar ${ }^{16}$, pues desde la segunda mitad del s. XI se asiste a una irrupción masiva de leones en todo tipo de soportes; parafraseando a Pastoureau, el león es la vedette en la Edad Media:

"El león, en la Europa cristiana medieval, no es verdaderamente una fiera exótica y desconocida, sino un animal que puede verse, pintado o esculpido, en todas las iglesias y que casi forma parte de la vida cotidiana, como el dragón" ${ }^{17}$.

Obviamente, a diferencia de este último, el león es un animal auténtico que se ve en las casas de fieras, pues desde el s. XII muchas ciudades y cabildos, a imitación de las casas reales y nobleza, contaban con su propia ménagerie.

En el caso de la cultura visual medieval hispana, el león también tiene un lugar señalado dentro de las prácticas artísticas islámicas. Así pues, por ejemplo, el tópico de la bravura del león trascendería todas las culturas peninsulares, entre cristianos, musulmanes o judíos. En el ámbito islámico, el león es también una imagen omnipresente, no sólo en las piezas eborarias andalusíes, esculturas de piedra o de bronce surtidoras de fuentes (leones del Māristān, león de Monzón, etc.), sino también en la literatura, como en la obra de Ibn Bajtisu o "El libro de las utilidades de los animales" (s. XI) o en las distintas versiones ilustradas de "Kalīla wa Dimna", bien conoci-

\footnotetext{
13 A. SOLER DEL CAMPO, “Armas y armaduras en las Cantigas de Alfonso X El Sabio”, L. FERNÁNDEZ y J.C. RUIZ SOUZA (eds.), op. cit., 2011, p. 265.

14 M.L. MARTÍN ANSÓN, "La orfebrería: ajuar cortesano y ajuar litúrgico", L. FERNÁNDEZ y J.C. RUIZ SOUZA (eds.), op. cit., 2011, p. 328.

15 Cfr. Libro del Ajedrez, Dados y Tablas, 1283, Biblioteca del Monasterio de San Lorenzo de El Escorial, Ms T-I-6, fol. 8r.

16 El león de la placa de cinturón de la Ermita Virgen de la Torre se asemeja a distintas representaciones de leones datadas también en el s. XIII, tales como la del Ms Ashmolean 1511, fol. 11r; el león central del estuche de cordobán repujado de la cruz de las Navas de Tolosa (Monasterio de Santa María la Real de Huelgas, Patrimonio Nacional, $\mathrm{n}^{\circ}$ inv. 00650536); los leones de los relieves de uno de los sarcófagos del Monasterio de Santa María la Real de Huelgas con escudos blocados con águila y león pasante (ca. 1209-1230); el león del fresco de San Pedro de Arlanza, ca. 1200 (The Cloisters Collection, n 1931, Nueva York); o el de un sello de plomo del rey Fernando III de 1232 (AHN, silografía C.5/3).

17 M. PASTOUREAU, Una historia simbólica de la Edad Media occidental, Buenos Aires, 2006, p. 19.
} 
das no sólo en al-Andalus, en versión árabe, sino también en la traducción castellana ordenada por Alfonso X ( $c a$. 1251).

No obstante, y teniendo como referencia la cultura visual medieval castellana, el estudio de estas piezas permitiría argumentar algunas consideraciones de tipo sociocultural algo más profundas. La morfología y decoración de la placa de cinturón con león de la Ermita Virgen de la Torre (Madrid) nos remite a otras piezas completas también doradas como el broche de cinturón hallado en un enterramiento de la Capilla del Obispo en el conjunto de San Andrés de Madrid (Fig. 1,9) ${ }^{18}$, que nos aseguraría su uso como hebilla de cinturón -pero su datación en un contexto funerario posterior al s. XIV (T-83), teniendo en cuenta la cronología del resto de la producción, indicaría su pervivencia como objeto de lujo-, o una de las hebillas de Calatrava La Vieja que presenta un motivo de una cruz patada astada e inserta en un escudo (Fig. 2,11), que sus excavadores han puesto en relación con la presencia de la orden del Temple en el castillo calatravo, en la segunda mitad del s. XII (1147-95) ${ }^{19}$, justo antes de volver la plaza a manos almohades. Sin embargo, hay autores como Menéndez Pidal que piensa que en este momento histórico la forma de cruz patada no parece específica de ninguna orden militar concreta. De hecho, no deja de llamar la atención su similitud con la cruz astada de Ainsa, cuyo prototipo se encuentra ya en monedas de Alfonso I de Aragón, con un origen legendario casi idéntico a la cruz asturiana ${ }^{20}$. Por desgracia, en el mercado de antigüedades también se hallan hebillas similares, en este caso la figura de un león contornado (Fig. 1,10) ${ }^{21}$.

Creo que estos ejemplos nos aproximan a una mejor comprensión del lenguaje de estos pequeños objetos de adorno indumentario: nos encontramos ante imágenes para-heráldicas, puesto que el fenómeno emblemático ya habría hecho su aparición a inicios del s. XII -el período de formación del sistema heráldico hispano se fijaría entre 1135 y $1225-^{22}$, de modo que, ya en el s. XIII, no es sorprendente que esos signos se expandan fuera del ámbito de la realeza y mundo militar, afectando a múltiples segmentos de la sociedad medieval hispana. Lo que explicaría su hallazgo en yacimientos del entorno toledano. La corona de Castilla usa el león, primero como señal y después en armerías desde Alfonso VII, quien lo introduce en sus monedas tras proclamarse emperador en $1135^{23}$. Y como se trata de una señal, sólo la hereda

18 V. PEÑA, "Intervención arqueológica en la Capilla del Obispo en el Conjunto Monumental de San Andrés en Madrid", Actas de las IV Jornadas de Patrimonio Arqueológico en la Comunidad de Madrid, Madrid, 2009, p. 91, fig. 12.

19 Ref. CV-06/29/440/21; medidas: longitud 66,5 mm; anchura placa 42,4 mm; anchura hebilla 58,6 mm; grosor hebilla 6,9 mm; grosor placa 1,1 mm; peso 55,54 gr. (J. BARRIO et al., "Catálogo y estudio de piezas doradas medievales", J. BARRIO y J. CHAMÓN (eds.), Proyecto Dorados. Tecnología, conservación y restauración de los metales dorados medievales, Madrid, 2010, pp. 85-87).

20 F. MENÉNDEZ PIDAL, "El blasón de la villa de Cintruénigo y las armas de Sobrarbe", J. MARTÍNEZ DE AGUIRRE (ed.), Homenaje a Faustino Menéndez Pidal de Navascués, Príncipe de Viana, 241 (2007), p. 381. Aprovecho la ocasión para agradecer al Dr. Martínez de Aguirre esta referencia bibliográfica sobre la cruz de Ainsa.

21 Alcalá Subastas, lote 287: http://www.alcalasubastas.es/es/localizador (consulta: 18/12/2012).

22 F. MENÉNDEZ PIDAL, Leones y castillos. Emblemas heráldicos en España, Madrid, 1999, pp. 22-23.

23 F. MENÉNDEZ PIDAL, Heráldica medieval española I. La casa real de León y Castilla, Madrid, 1982, p. 24. 
Fernando II (1157-1188), y es este rey quien convierte la antigua señal del león en las armas del Reino de León.

Por otro lado, pese a que se haya propuesto una manufactura almohade para algunas de las hebillas de cinturón doradas, por supuestos paralelos en el Algarve portugués, concretamente: unas placas cuadrangulares simples con las charnelas recortadas y dobladas (a diferencia del grupo anterior, nunca se trata de la placa entera y doblada sobre sí misma) y dos orificios en el extremo para los remaches de sujeción al cinto y que presentan un cuadrúpedo pasante a la izquierda con collar, como las halladas en Calatrava la Vieja (Fig. 2,15) ${ }^{24} \mathrm{o}$ en el yacimiento conquense de Valeria de Arriba (Fig. 2,16) ${ }^{25}$, creo que todos los motivos decorativos registrados, incluso éstos, se integrarían mejor dentro de la cultura visual cristiana (independientemente de quién pudiera haberlos fabricado). A estos ejemplos, se suman otros tan similares entre sí que permiten establecer que se trata de una manufactura seriada, como una placa de cinturón conservada en el Museo Arqueológico Nacional (Fig. 2,17) ${ }^{26}$ y otras tres del Museo de Ciudad Real (Fig. 2,12-14) ${ }^{27}$, todas de procedencia desconocida. Si identificamos estas imágenes con un perro con collar, como es posible que así sea (en ningún caso, presentan las incisiones curvas en el cuello que denotan la representación de la melena, a diferencia de las piezas madrileñas), este signo sólo tendría una connotación positiva dentro de la cultura cristiana: los perros son los emblemas más habituales de la nobleza feudal e incluso, en época posterior, los propios reyes son comparados con "alanos creçidos" 28 . Además, a este hecho se suma el detalle de la proporción de oro/mercurio atestiguada en las piezas de Calatrava y Valeria, más acorde con los parámetros de las hebillas consideradas de fabricación "cristiana" 29 . A los emblemas de cruces y leones, se podrían añadir los de castillos y lobos que también se emplean para decorar las placas de cinturón del s. XIII. En el primer caso, contamos con otro ejemplar del Museo Arqueológico Nacional (Fig. 2,18); y en el segundo, una placa de bronce del yacimiento de Silveirona (Estremoz, Portugal), cuya asignación cronológica podría ser dudosa, pues su hallazgo en el nivel superficial de una necrópolis tardo-antigua nos permite sospechar que la cronología propuesta del

24 Ref. CV-07/24/73. Medidas: longitud 52,9 mm; anchura 41,6 mm; grosor 2,4 mm; peso 15,96 gr (J. BARRIO et al., op. cit., 2010, pp. 56-57).

25 Ref. S-4-87a. Medidas: longitud 48,4 mm; anchura 39,1 mm; grosor 1,2 mm; peso 19,36 gr (J. BARRIO et al., op. cit., 2010, pp. 99-101).

26 Mi más sincero agradecimiento a Isabel Arias, conservadora del Museo Arqueológico Nacional, no sólo por la noticia sobre ésta y las otras tres placas de cinturón conservadas en ese museo, sino también por su generosa disposición al permitirme darlas a conocer aquí.

27 Medidas de la pieza $n^{\circ} 12: 54$ x 40 mm: medidas de la pieza $n^{\circ} 13: 44$ x 34 mm; medidas de la pieza $n^{\circ}$ 14: 47 x 42 mm. La decoración de las placas de cinturón del Museo de Ciudad Real, aunque ha sido identificada con grifos pasantes, la ausencia manifiesta de alas en estas figuraciones desaconsejaría dicha atribución. Además, existe una discrepancia entre la fotografía de esta publicación y la descripción del texto del catálogo, donde se indica que los cuadrúpedos miran a la izquierda, extremo que me he permitido corregir en las ilustraciones que aquí se aportan (J. ZOZAYA, "Placas de cinturón", J. ZOZAYA (ed.), Alarcos '95: el fiel de la balanza, Toledo, 1995, p. 276).

28 A.I. CARRASCO, "La metáfora animal en la propaganda política de los Reyes Católicos (1474-1482)", Cahiers de Linguistique et de Civilisation hispaniques médiévales, 25 (2002), p. 405.

29 J. CHAMÓN, op. cit., 2010, p. 141. 
s. VI, quizá no sea tan segura (Fig. 2,19) ${ }^{30}$. Esto es especialmente evidente cuando se observa la técnica decorativa, a base de pequeñas impresiones circulares de cincel de orfebre que conforman el fondo y los detalles anatómicos, mucho más cercana a las placas castellanas del s. XIII que a los adornos de época visigoda. Así pues mediante estos ejemplos (cruz patada, león, castillo, perro con collar, lobo), parece claro el vínculo que presentan estas placas de cinturón con los motivos heráldicos coetáneos de los reinos hispanos.

De este modo, y siguiendo los parámetros de la tradición heráldica, en la que los animales empleados tienen una connotación positiva (leones, perros, lobos ...) $)^{31}$, con la analogía en la base de su sistema iconográfico que establece redes de significado por parecidos o correspondencias entre cosas e ideas, entre lo visible y lo arcano, entre lo terrenal y lo escatológico, las imágenes para-heráldicas representadas en las placas de cinturón, hipotéticamente, deberían de reflejar una misma escala de valores, a diferencia de otros emblemas animales (como los dragones) que tienen una lectura negativa para el observador cristiano coetáneo (los ejemplos de prácticas pre-heráldicas reflejadas en la Chanson de Roland, de finales del s. XI, donde las insignias de los ejércitos musulmanes están plagadas de dragones) ${ }^{32}$. Siguiendo el planteamiento que aquí sostengo, muchas de las figuras de las placas de cinturón halladas en Madrid, Cuenca o Ciudad Real sólo podrían tener una connotación positiva dentro de los parámetros culturales de los reinos cristianos, un extremo más evidente en el caso de las cruces y de los cuadrúpedos con collar.

Pero ¿cómo son las piezas de adorno equiparables en el mundo andalusí? En primer lugar, no está de más recordar que hace ya mucho tiempo que Prinet y Mayer demostraron, a inicios del s. XX, que fue la heráldica occidental la que influyó en los usos musulmanes y no a la inversa ${ }^{33}$. La heráldica es un fenómeno occidental y no un préstamo cultural traído por los cruzados a Europa. Una pieza de plata, morfológicamente cercana a las castellanas, es la hallada en Castillo de Puentes en Lorca, tanto en forma, módulo y cronología, pues se data en la primera mitad del s. XIII -la disposición del epígrafe indicaría que podría tratarse de una delicada hebilla de tahalí- (Fig. $5,26)^{34}$. En este caso, el campo cuadrado de la placa está cubierto por una decoración epigráfica: aquí el texto árabe (al-baraka: la bendición) se contrapone al animal protector cristiano. Más adelante, incluso, vemos cómo los escudos musulmanes prefieren adoptar una visualización emblemática típicamente islámica con lemas coránicos. Aunque evidentemente, no se trate de un motivo propiamente heráldico, no será hasta finales del s. XIV cuando los nazaríes adopten el escudo con el lema de su dinastía

\footnotetext{
30 Medidas: 35 x 26 mm; grosor 2 mm. C. FABIÃO, M.S. DIAS y M. CUNHA, Sit Tibi Terra Leuis. Rituais funerários romanos e paleocristãos em Portugal, Lisboa, 2008, p. 51.

31 M.D.C. MORALES, "Leones y águilas. Política y sociedad medieval a través de los símbolos faunísticos", M.P. GARCÍA HUERTA y F. RUIZ GÓMEZ (eds.), Animales simbólicos en la historia. Desde la protohistoria hasta el final de la Edad Media, Madrid, 2012, p. 218.

32 M. NEUMEYER, "Le bestiaire héraldique. Une mirroir de la chevalerie", Micrologus, 8.1 (2000), p. 149.

33 F. MENÉNDEZ PIDAL, op. cit., 1999, p. 164.

34 A. PUJANTE, "El castillo, la alquería y maqbara de Puentes (Lorca, Murcia)", Memorias de Arqueología, 14 (1999), p. 542.
} 
que aplican, al igual que los cristianos, en diferentes soportes, distintos del ámbito estrictamente militar (azulejería de la Alhambra, espadas jinetas nazaríes, etc.).

Pareciera que toda vez que la representación de un motivo decorativo, en ciertos contextos militares de los reinos cristianos, adopte un carácter de emblema en el sentido de un signo que indica la identidad de un individuo o de un grupo de individuos, como pueda ser un escudo de armas; automáticamente y, por oposición, la cultura andalusí adoptaría otros sistemas de representación para sus grupos de individuos fácilmente distinguibles e inequívocos. En este sentido, los leones rampantes del Pendón de Las Navas aunque Fernández-Puertas en algún momento haya sugerido que son parte del tejido original ${ }^{35}$, Herrero Carretero, conservadora de tejidos de Patrimonio Nacional, observa que los tres leones rampantes tejidos en círculos enlazados son añadidos antiguos, muy probablemente realizados en el s. XIII, cuando el pendón pasó a manos cristianas, bien como botín tras la legendaria batalla de Las Navas (1212) o durante las conquistas andaluzas de Fernando III (Fig. 6). Un caso similar de apropiación cultural ha sido determinado por Ruiz Souza y Calvo Capilla en la puerta de madera de la sacristía del monasterio de Las Huelgas de Burgos, donde se observa la extracción de piezas ¿de carácter islámico? que fueron sustituidas mediante la incrustación del emblema de castillos de Alfonso VIII ${ }^{36}$.

\section{Las hebillas para-heráldicas hispanas, ¿indicadores de repoblación?}

El estudio detallado de este tipo de piezas aún se encuentra en sus inicios. Pero por lo que conocemos de la cultura material de otros reinos peninsulares vecinos, esta tipología de hebillas, con ciertas variantes, parece asociarse a una producción local del Reino de Aragón, que desde finales del s. XIII parece extenderse a las antiguas ciudadelas reales fronterizas situadas en Midi-Pyrénées, en Languedoc y Provenza donde, a su vez, se consideran, siguiendo a Barrère, una manufactura local fechada entre finales del s. XIII e inicios del XIV y que, al igual que las piezas castellanas o aragonesas, exhiben trazas de dorado y restos de esmaltado: fortaleza de Peyrepertuse en Carcasona (Fig. 2,25), Montségur, Durfort (Tarn), Montburn-Bocage (Haute-Garonne) o Saint-Vincent d'Olargues (Hérault) ${ }^{37}$. La diferencia con el grupo castellano consiste en la forma rectangular muy alargada de las placas, de un tamaño considerablemente menor, la presencia de remaches múltiples (lo que presupone una necesidad de mayor firmeza de la sujeción de la placa al cinto y, presumiblemente, su uso en arreos de montura) y en el predominio de motivos geométricos y vegetales en la decoración de las hebillas francesas, salvo la bella pieza hallada en un enterramiento del panteón del claustro de Saint-Émilion de Gironda, actualmente conservada en

35 A. FERNÁNDEZ-PUERTAS, "Pendón de Las Navas de Tolosa", J. YARZA (coord.), Vestiduras ricas. El monasterio de Las Huelgas y su época, 1170-1340, Madrid, 2005, pp. 262-267.

36 Agradezco enormemente la generosidad del Dr. Ruiz Souza al compartir esta información inédita que es objeto de un estudio conjunto con la Dra. Calvo Capilla, en curso de elaboración.

37 M. BARRÈRE, "Metal (alliage cuivreux)", L. BAYOU (dir.), Peyrepertuse. Fortresse royale, Archéologie du Midi Médiéval, Supplément, 3 (2000), pp. 213-235. La pieza de Peyrepertuse, aquí ilustrada, corresponde a la fig. 146, 2. 
el Museo de Aquitania (Burdeos), de bronce dorado con una decoración en relieve que muestra a un basilisco luchando contra un áspid ${ }^{38}$.

Las piezas localizadas en Cataluña se suelen asociar al reinado de Jaime I (12131276). El módulo de estas hebillas como las francesas, y a diferencia de las castellanas, es menor y esencialmente rectangular y los campos de fondo son lisos, predominando las decoraciones vegetales y geométricas. Algunas de ellas, como el tipo de placa de cinturón con un león rampante esquemático a la izquierda inserto en un medallón (Fig. 2,23), se ha vinculado con ambientes judíos, como las halladas en la necrópolis judía de Gerona ${ }^{39}$, en la judería de Barcelona o en Santa Creus de Llagunes (Pallars Subirà) ${ }^{40}$, aunque también se encuentran en L'Esquerda de Roda de Ter, un asentamiento abandonado a finales del s. XIII ${ }^{41}$. Recientemente, en las excavaciones realizadas en la calle de Sant Honorat, en la plaça Comercial, o en el mercado del Born de Barcelona se han hallado algunas piezas doradas al fuego con un motivo de árbol ahojado inserto en un campo pentagonal, que Beltrán de Heredia y Font han identificado con otra producción local independiente de la castellana ${ }^{42}$. Otras hebillas halladas más al sur se registran en la ciudad de Lérida ${ }^{43}$; en la calle de Sant Joan de Burriana (Castellón), se hallaron dos piezas con restos de dorado fechadas a mediados del s. XIII, una de ellas con una decoración de escudo que ha pasado inadvertida ${ }^{44}$; en Jijona (Alicante) ${ }^{45}$; o en el salón norte de la casa 6 de Siyāsa (Cieza, Murcia), en un contexto de mediados del s. XIII; esta última destaca por su decoración calada y resulta del ensamblaje de tres placas cuadradas con decoración de cruces y castillos $^{46}$. Todas estas piezas se suelen vincular con la llegada de repobladores catalano-aragoneses a la zona levantina.

Algunas piezas de cinturón del s. XIII combinan la decoración cincelada con el fondo esmaltado sobre el que resalta la figura, como una pieza de Calatrava la Vieja que presenta castillos esquemáticos u otra placa de la misma procedencia decorada

38 Ref. $\quad \mathrm{n}^{\mathrm{o}}$ inv. D.80.2.118; http://www.musee-aquitaine-bordeaux.fr/es/articulo/hebilla-decintur\%C3\%B3n-decorada-con-un-grif\%C3\%B3n (consulta: 20/11/2013).

39 J. CASANOVAS, "Las necrópolis judías hispanas. Nuevas aportaciones", I. BANGO (ed.), Memoria de Sefarad, Madrid, 2002, p. 210.

40 J. ROIG, "Els materials de ferro i de bronze del vilatge medieval de Santa Creu de Llagunes (Soriguera, Pallars Sobirà", Actes del II Congrés d'Arqueologia Medieval i Moderna a Catalunya (Sant Cugat del Vallès, 2002), San Cugat del Vallès, 2003, p. 841; fig. 2, 24.

41 I. OLLICH, "Hebillas medievales procedentes de Roda de Ter", Atti del Colloquio Internazionale (Palermo-Erice, 1974), Palermo, 1976, pp. 505-516.

42 J. BELTRÁN DE HEREDIA y L. FONT, "Un conjunt de sivelles de coure amb aplicació d'or de producció local”, Quaderns d'Arqueologia i Història de la Ciutat de Barcelona, 7 (2011), pp. 180-191.

43 L. AMENÓS y A. LORIENTE, "Hebillas de bronce de época medieval recuperadas en la ciudad de Lleida: estudio documental, iconográfico y arqueológico", International Medieval Meeting, Universitat de Lleida, 2012, en prensa.

44 S. DELAPORTE y F. LÓPEZ BRAVO, “Objetos metálicos de época medieval procedentes de recientes excavaciones urbanas en Burriana”, J.M. MELCHOR, J. BENEDITO y T. PASÍES (eds.), La arqueología de la Buriyyana islámica a la Borriana cristiana, Burriana, 2011, pp. 127-128, lám. 1, nº 6 .

45 La pieza de Jijona sólo conserva la placa de cinturón rectangular y cinco remaches, 44 x $18 \mathrm{~mm}$, y se data entre los ss. XIII-XIV (R. AZUAR, Castillo de la Torre Grossa (Jijona), Alicante, 1985, p. 101; lám. L, 7080).

46 J. NAVARRO y P. JIMÉNEZ, "Hebilla castellana”, I. BANGO (dir.), Alfonso X y su época, Murcia, 2009 , p. 752. 
con leones leopardados pasantes a la izquierda ${ }^{47}$. Esta última pieza también es producto de una fabricación en serie pues una pieza esmaltada inédita y casi idéntica se conserva en el Museo Arqueológico Nacional (Fig. 2,20). Otro ejemplar esmaltado más completo, quizá algo más tardío, corresponde al recuperado en las excavaciones arqueológicas de la iglesia de San Martín de Iraurgi (Azkoitia), con dos escudos acuartelados (Fig. 2,24) . $^{4}$

Finalmente, cabría destacar la presencia de algunas variantes de hebillas con la placa calada, técnicamente muy similares a la anteriormente mencionada de Siyāsa, como una pieza inédita, de procedencia desconocida, que se conserva en el Museo Arqueológico Nacional y presenta en par heráldico a dos leones rampantes afrontados a una especie de "estandarte" con cuatro círculos en hueco - ¿vista aérea de un castillo con cuatro torres?- (Fig. 2,21), o la placa recientemente localizada por Andréu en las excavaciones de la Plaza de la Armería de Madrid que muestra el escudo acuartelado de Fernando III (Fig. 2,22) ${ }^{49}$. Creo que el calado de ambas piezas reforzaría su carácter para-heráldico, pues permitiría jugar con la visibilidad del color del cinto, y por tanto aproximarse más a las genuinas prácticas heráldicas. Por lo que sabemos de este tipo de motivo "scutulado", su uso se remonta a Alfonso VIII, y su aplicación a las "telas ricas" se restringiría inicialmente a miembros de la Corona ${ }^{50}$. En este sentido, es difícil valorar este hallazgo en la judería de Madrid. Quizá, coincidiendo con las observaciones de Menéndez Pidal quién ya detectó la extensión de este tipo de emblemas entre las clases populares y en la ornamentación de los objetos cotidianos, el emblema castellano haya perdido su función exclusivamente identificadora, invadiendo la ornamentación de la vestimenta ${ }^{51}$. Así como las armas reales llevadas in signo subiectionis reportan al usuario una especie de protección y prestigio ante los demás, con o sin autorización real, por simple imitación e incluso para sencillamente subrayar la patria de su portador ${ }^{52}$, de este modo podría entenderse la decoración pictórica del sepulcro del obispo D. Rodrigo Díaz (m. 1339) en la capilla de San Martín de la catedral vieja de Salamanca.

47 J. BARRIO et al., op. cit., 2010, p. 66 y p.75.

48 M.D. GEREÑU, "Ermita de San Martín de Iraurgi (Azkoitia)”, Arkeoikuska, 94 (1994), p. 209.

49 E. ANDRÉU y V. PAÑOS, "Nuevas propuestas de ubicación espacial de la judería medieval de Madrid: evidencias arqueológicas", Revista Historia Autónoma, 1 (2012), pp. 66-67, fig. 11. Ref. A2/1073/24. Medidas: longitud 53,2 mm; anchura $46,9 \mathrm{~mm}$; grosor $0,7 \mathrm{~mm}$.

50 C. HERRERO, "El museo de telas medievales de Santa María la Real de Huelgas. Colecciones textiles de Patrimonio Nacional", J. YARZA (coord.), op. cit., 2005, pp. 119-138.

51 L. RODRÍGUEZ PEINADO, "El arte textil en el siglo XIII. Cubrir, adornar y representar: una expresión de lujo y color", L. FERNÁNDEZ y J.C. RUIZ SOUZA (eds.), op. cit., 2011, p. 347.

52 F. MENÉNDEZ PIDAL, op. cit., 1982, p. 243. 


\title{
Catálogo de una selección de piezas ${ }^{53}$
}

\author{
Ermita Virgen de la Torre (Fig. 1; Fig. 3).
}

1. Aplique claviforme de cobre dorado (06-46-Y.79317-XI-sup-1). La cabeza del aplique tiene forma de roseta de 6 pétalos y una punta central de sección cuadrangular. Medidas: diámetro cabeza $32 \mathrm{~mm}$; altura $23 \mathrm{~mm}$; grosor medio $3 \mathrm{~mm}$. Contexto: hallazgo superficial en el sector XI. Una pieza muy similar de Casarrubios se ha datado en el s. XV avanzado ${ }^{54}$.

2. Cascabel con restos superficiales de dorado (06-46-Y.79029-1645-2). Forma ovoide con 7 pequeños orificios circulares. Hacia la mitad de la pieza presenta una banda en relieve con una decoración incisa de trazos oblicuos que, en ocasiones, se entrecruzan. Presenta una arandela de suspensión y una pequeña piedrecilla de cuarzo en su interior para emitir el sonido al moverse. Medidas: altura 37,23 mm; longitud 30,64 mm; anchura $26,66 \mathrm{~mm}$; grosor medio $0,76 \mathrm{~mm}$. Contexto: estrato de amortización de una calicata minera para extracción de sílex, junto con materiales cerámicos fechados en el s. X(U.E. 1645).

3. Hebilla de bronce (06-46-Y.79029-1257-1). Hebilla de doble pasador. Medidas: longitud 52,13 mm; anchura 28,10 mm; grosor 2,76 mm. Contexto: nivel superficial de amortización, relacionado con el abandono y ruina del poblado, junto a varias llaves de hierro, ss. X-XI (U.E. 1257).

4. Hebilla de bronce (06-46-Y.79029-1644-21). Hebilla semicircular con una depresión en la zona del hebijón (perdido). Medidas: longitud 57,23 mm; anchura 33,04 mm; grosor 2,12-7,28 mm. Contexto: nivel contaminado, con materiales preferentemente datados en los ss. X-XI, aunque también se documentan algunas lozas de los ss. XIV-XV (U.E. 1644).

5. Hebilla de bronce (06-46-Y.79029-1581-1). Hebilla de forma oval y sección circular, con una depresión en la zona del hebijón (perdido). Ligeramente deformada. Medidas: longitud 35,67 mm; anchura 29,98 mm; grosor 2,10-5,93 mm. Contexto: estrato de amortización de un silo subaéreo, junto con materiales cerámicos del s. X (U.E. 1581).

6. Placa de cinturón de latón dorado (06-46-Y.79029-1784-1). Placa rectangular con dos lengüetas recortadas sobre la misma placa como charnelas, así como dos orificios para los remaches de ajuste al cinto. La pieza está decorada a base de una impronta de círculos con punto central dispuestos en el borde exterior y, en la zona central, agrupados entorno a un círculo impreso de mayor tamaño. Medidas: longitud 48,60 mm; anchura $34,58 \mathrm{~mm}$; grosor $0,68 \mathrm{~mm}$; peso 4,4 gr. Contexto: estrato de amortización de un silo subaéreo, junto con materiales cerámicos fechados entre los ss. X-XI (U.E. 1784).

7. Hebilla de cobre "dorado al fuego" (06-46-Y.79029-1856-3). Hebilla en forma de arco y sección rectangular, con una decoración incisa a base de trazos paralelos entre líneas que siluetean la forma de la propia hebilla. Medidas: longitud 54,19 mm; anchura

\footnotetext{
53 Sólo se incluye la descripción de las piezas de la Ermita Virgen de La Torre y de las piezas inéditas del Museo Arqueológico Nacional.

54 Ref. SECYR 21. Medidas: diámetro cabeza $35 \mathrm{~mm}$; espesor medio $6 \mathrm{~mm}$; peso 11,58 gr (J. BARRIO et al., op. cit., 2010, pp. 102-103).
} 
26,15 mm; grosor 4,66 mm; peso 19,7 gr. Contexto: firme de la calzada U.E. 1933, con un predominio absoluto de materiales fechados entre los ss. X-XI (U.E. 1856).

8. Placa de cinturón de cobre "dorado al fuego" (06-46-Y.79029-1744-1). Placa cuadrangular doblada sobre sí misma con recorte extractivo rectangular para la hebilla (perdida). Presenta una decoración de un león pasante a la izquierda, con las fauces abiertas y la cola sinuosa levantada. Los detalles de la silueta, anatomía y campo del fondo realizados con pequeñas impresiones de cincel de orfebre de impronta circular. En el borde y la charnela, muestra incisiones perpendiculares y paralelas. En el extremo presenta dos orificios para los remaches (perdidos). Medidas: longitud $39 \mathrm{~mm}$; anchura 40,03 mm; grosor 1,47 mm; peso 16,1 gr. Contexto: estrato de amortización de un silo subaéreo, junto con materiales cerámicos fechados en los ss. XII-XIII (U.E. 1744).

\section{Museo Arqueológico Nacional (Figs. 2 y 4-5) ${ }^{55}$.}

17. Placa de cinturón de cobre dorado (MAN 1997/62/1). Placa simple cuadrangular con lengüetas de la charnela recortadas sobre la propia placa y dos orificios para los remaches (perdidos) en un extremo. Presenta una decoración a base de impresiones de cincel de orfebre de impronta circular e incisiones que definen a un cuadrúpedo pasante con collar a la izquierda. Detalles anatómicos, fauces abiertas y cola sinuosa levantada. Medidas: longitud 53,32 mm; anchura 45,5 mm; grosor 1,78 mm.

18. Placa de cinturón de cobre dorado (MAN 1997/62/2). Placa simple cuadrangular con lengüetas de la charnela recortadas sobre la misma placa y dos orificios para los remaches (perdidos) en un extremo. La decoración del castillo con entrada en arco, flanqueada por dos torres con merlones triangulares que destaca sobre un fondo de impresiones de cincel de orfebre de impronta circular y detalles arquitectónicos y de la charnela incisos. Medidas: longitud 45,45 mm; anchura 44,36 mm; grosor 1,4 mm.

20. Placa recortada de cobre dorado y esmaltada (MAN 1992/49/4). Placa simple cuadrangular con cinco orificios para remaches en un extremo, de los que conserva tres remaches de cabeza cónica. La decoración consiste en un león leopardado andante a la derecha, con las fauces abiertas y la cabeza frontal con ojos circulares; los detalles de la melena se realizan mediante incisiones oblicuas y reticuladas en el cuerpo; con la cola sinuosa levantada. Mientras que los detalles anatómicos están realzados mediante repujado de la propia placa (cabeza y cuartos traseros). El fondo de la pieza conserva un esmalte de color blanquecino. El extremo derecho de la pieza está recortado como producto de una reutilización. Medidas: longitud 31,32-31,9 mm; anchura 37,22-33,74 $\mathrm{mm}$; grosor medio $2 \mathrm{~mm}$; altura remache 3,99-4,01 $\mathrm{mm}$.

21. Placa calada de cobre dorado (MAN 1992/49/3). Placa rectangular con orificios para los remaches en los cuatro ángulos. La decoración calada está realizada mediante el recorte parcial de la pieza y consiste en dos leones rampantes afrontados a una especie de estandarte cuadrado con cuatro círculos. La superficie del "estandarte", así como la melena de los leones y parcialmente la cola de los animales está cincelada. Medidas: longitud 72,63-73,04 mm; anchura 34,08-33,71 mm; grosor medio $1 \mathrm{~mm}$.

55 Todas las piezas del Museo Arqueológico Nacional son de procedencia desconocida, producto de las donaciones de particulares o de anticuarios. 

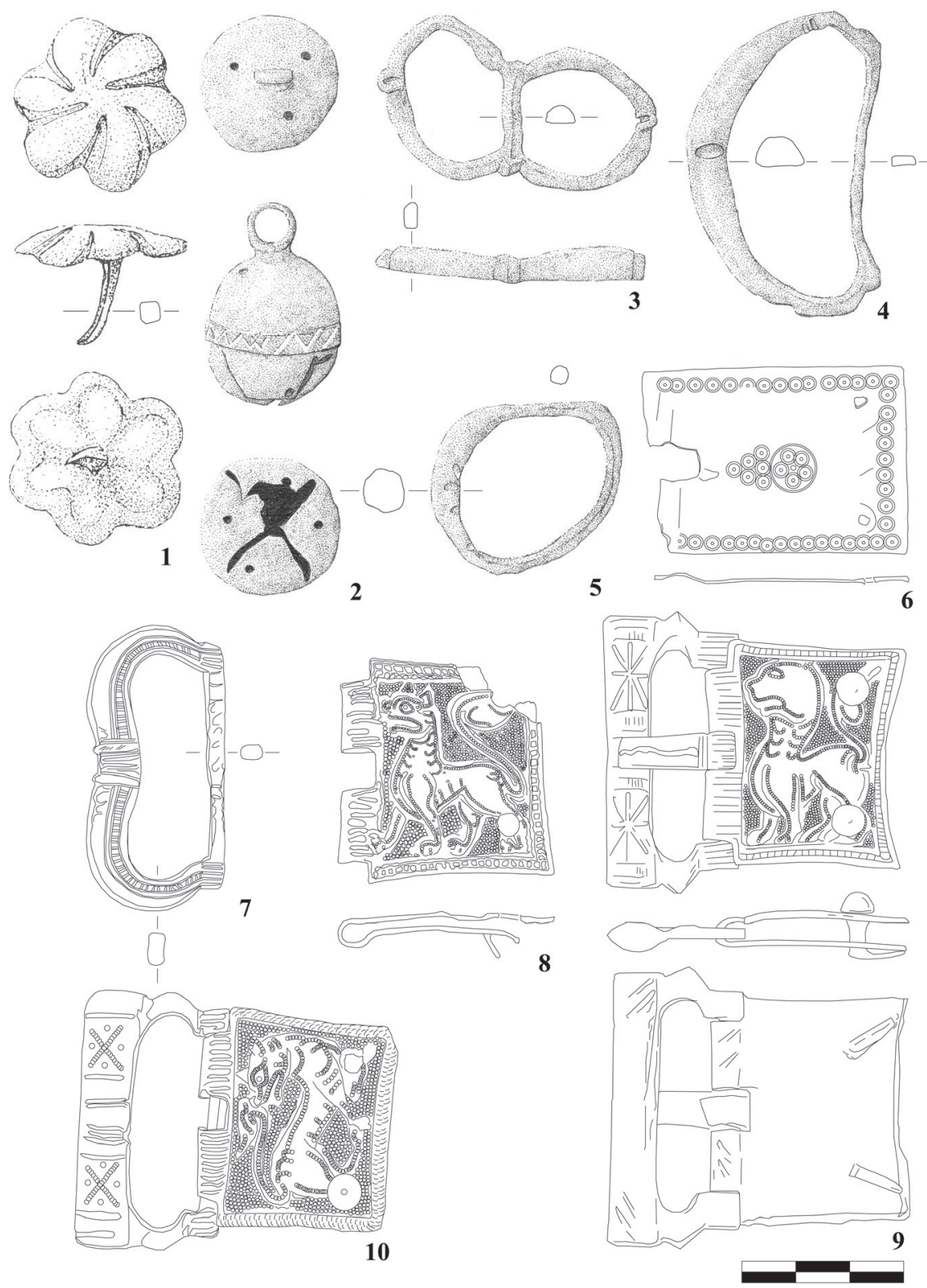

Fig. 1. Hallazgos de la Ermita Virgen de la Torre (Madrid): 1. Aplique claviforme (06-46-Y.79317-XI-sup-1); 2. Cascabel (06-46-Y.79029-1645-2); 3. Hebilla de pasador doble (06-46-Y.79029-1257-1); 4. Hebilla (06-46-Y.79029-1644-21); 5. Hebilla (06-46Y.79029-1581-1); 6. Placa de cinturón (06-46-Y.79029-1784-1); 7. Hebilla (06-46-Y.790291856-3); 8. Placa de cinturón (06-46-Y.79029-1744-1). 9. Hebilla de cinturón del enterramiento T-83 de la Capilla del Obispo de San Andrés de Madrid. 10. Hebilla de cinturón de procedencia desconocida (Subastas Alcalá, lote 287). 

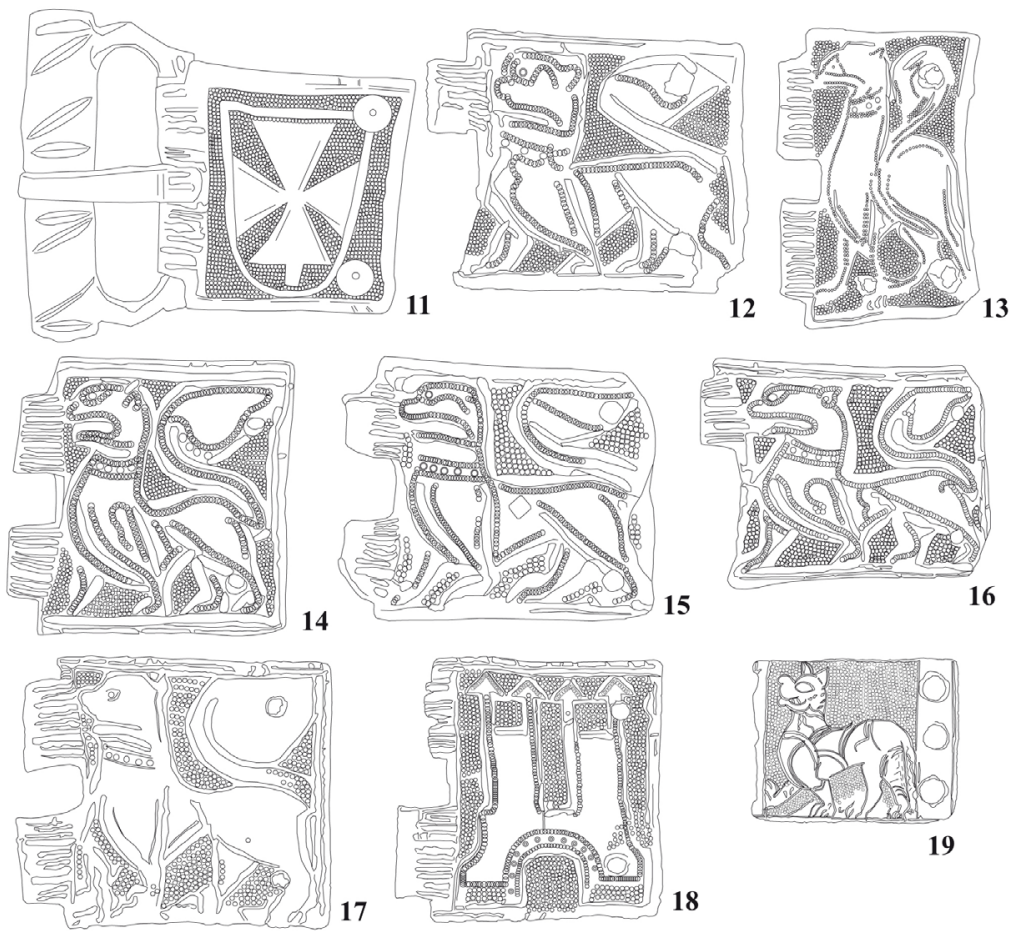

19
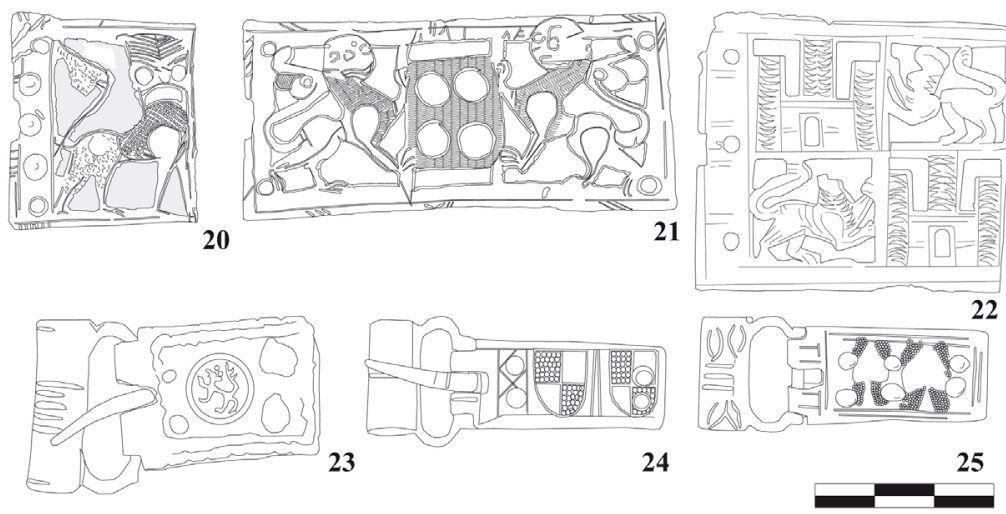

Fig. 2. 11. Hebilla de cinturón de Calatrava la Vieja, Ciudad Real (CV-06/29/440/21). 12-14. Placas de cinturón del Museo de Ciudad Real (s/n). 15. Placa de cinturón de Calatrava la Vieja (CV-07/24/73). 16. Placa de cinturón de Valeria de Arriba, Cuenca (S-4-87a). 17. Placa de cinturón del Museo Arqueológico Nacional (MAN 1997/62/1). 18. Placa de cinturón del Museo Arqueológico Nacional (MAN 1997/62/2). 19. Placa de Silveirona, Estremoz, Portugal (2003.54.1). 20. Placa esmaltada del Museo Arqueológico Nacional (MAN 1992/49/4). 21. Placa calada del Museo Arqueológico Nacional (MAN 1992/49/3). 22. Placa calada de la Plaza de la Armería, Palacio Real, Madrid (A2/1073/24). 23. Hebilla de cinturón de Barcelona. 24. Hebilla de cinturón de San Martín de Iraurgi, Azkoitia (SMI 93.CON.20). 25. Hebilla de cinturón de Peyrepertuse (Carcasona, Francia). 

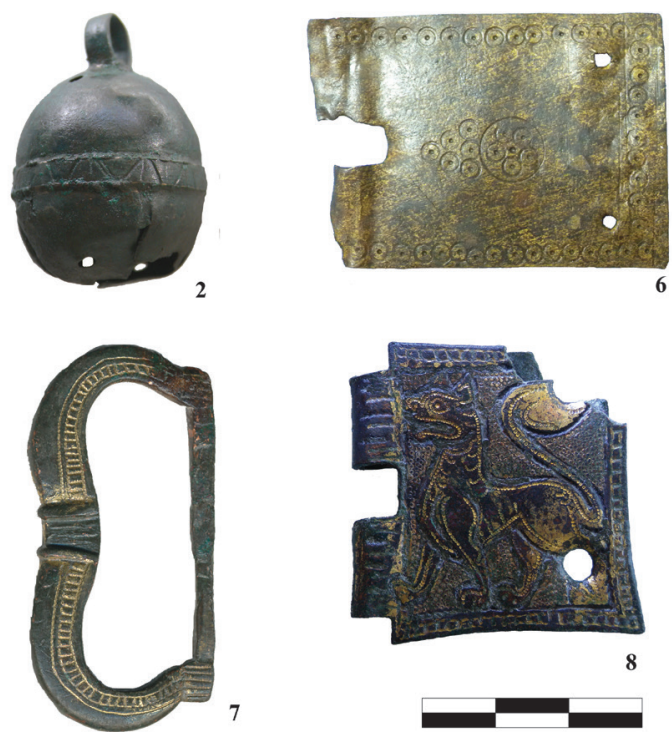

Fig. 3. Hallazgos de la Ermita Virgen de la Torre (Madrid): 2. Cascabel (06-46-Y.790291645-2); 6. Placa de cinturón (06-46-Y.79029-1784-1); 7. Hebilla (06-46-Y.79029-1856-3); 8. Placa de cinturón (06-46-Y.79029-1744-1).
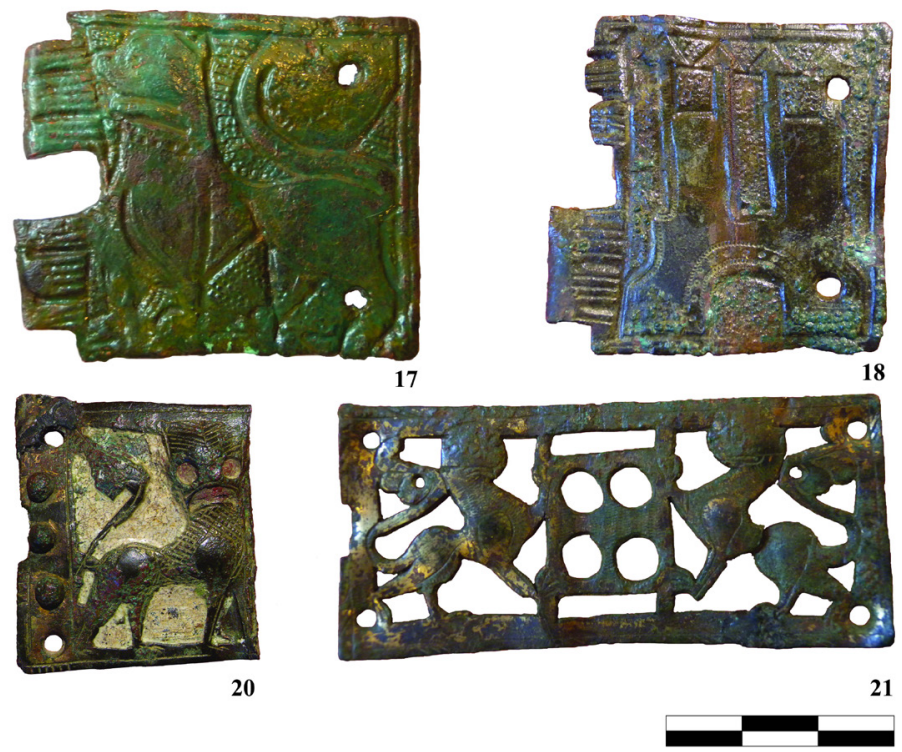

Fig. 4. Piezas del Museo Arqueológico Nacional: 17. Placa de cinturón (MAN 1997/62/1); 18. Placa de cinturón (MAN 1997/62/2); 20. Placa esmaltada (MAN 1992/49/4); 21. Placa calada (MAN 1992/49/3). 


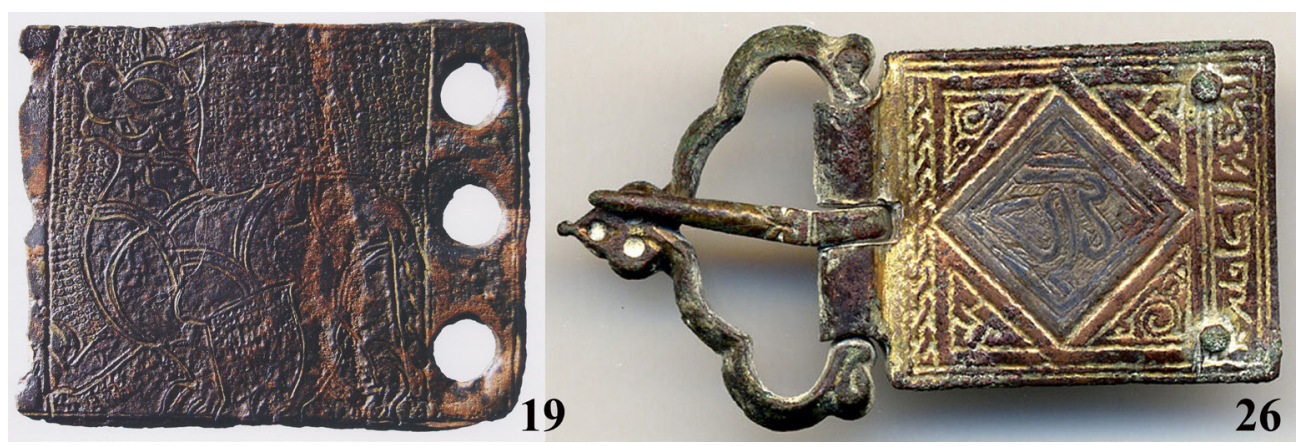

Fig. 5. 19. Placa de Silveirona, Estremoz, Portugal (2003.54.1). 26. Hebilla de Castillo de Puentes (Lorca, Murcia).
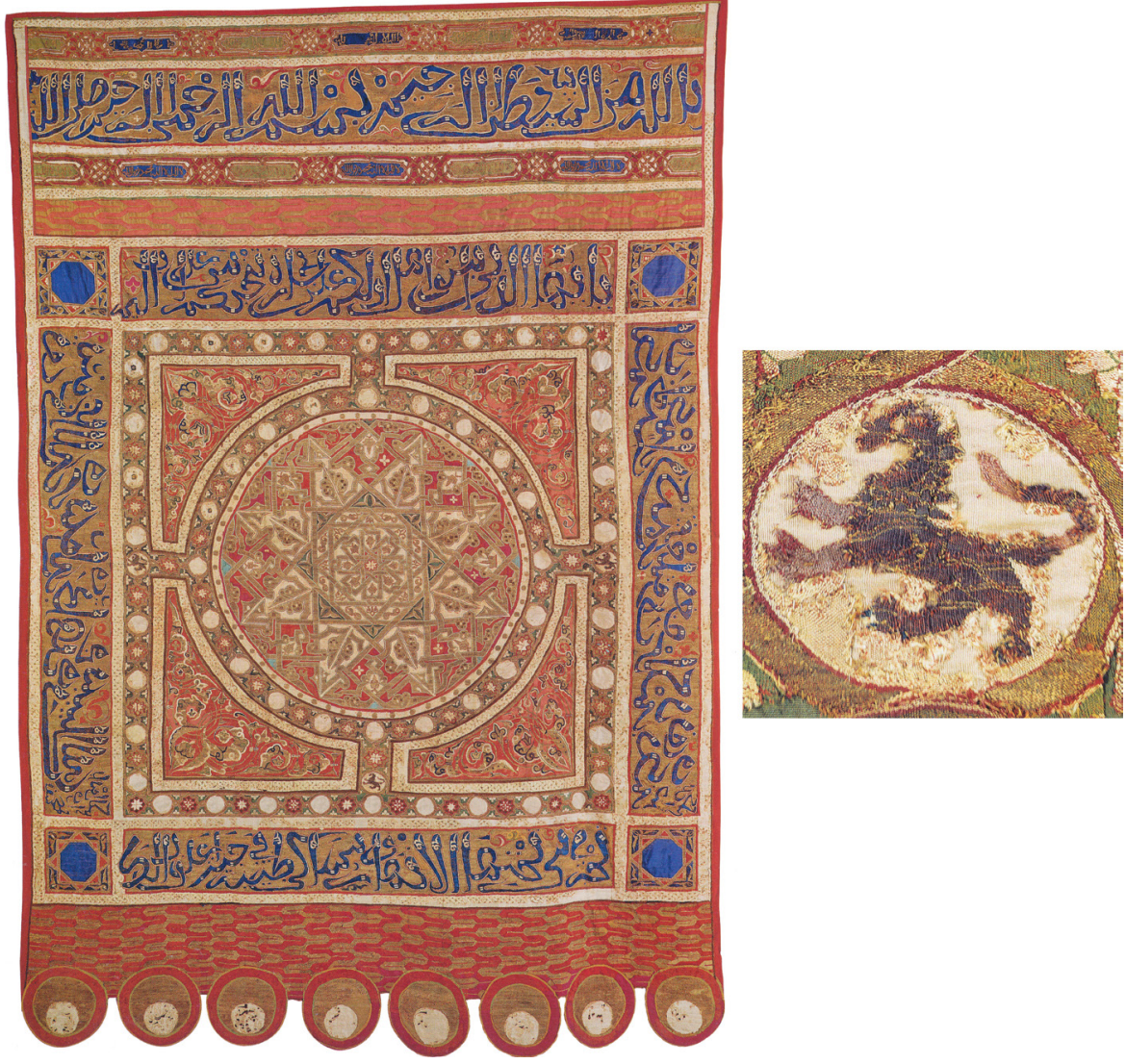

Fig. 6. Pendón de las Navas. Monasterio de Santa María la Real de Huelgas (Patrimonio Nacional, $\mathrm{n}^{\circ}$ inv. 00652193). 